\title{
Overexpression of the $\mathrm{S100A2}$ protein as a prognostic marker for patients with stage II and III colorectal cancer
}

\author{
TAIKI MASUDA $^{1}$, TOSHIAKI ISHIKAWA ${ }^{1}$, KAORU MOGUSHI $^{2}$, SATOSHI OKAZAKI $^{1}$, \\ MEGUMI ISHIGURO ${ }^{3}$, SATORU IIDA ${ }^{1}$, HIROSHI MIZUSHIMA ${ }^{4}$, HIROSHI TANAKA ${ }^{2}$, \\ HIROYUKI UETAKE $^{1}$ and KENICHI SUGIHARA ${ }^{1}$
}

\begin{abstract}
Departments of ${ }^{1}$ Surgical Oncology and ${ }^{2}$ Systems Biology, ${ }^{3}$ Translational Oncology, and ${ }^{4}$ Medical Omics Informatics, Tokyo Medical and Dental University Graduate School of Medicine, Tokyo 113-8510, Japan
\end{abstract}

Received October 18, 2015; Accepted December 17, 2015

DOI: $10.3892 /$ ijo.2016.3329

\begin{abstract}
We aimed to identify a novel prognostic biomarker related to recurrence in stage II and III colorectal cancer (CRC) patients. Stage II and III CRC tissue mRNA expression was profiled using an Affymetrix Gene Chip, and copy number profiles of 125 patients were generated using an Affymetrix $250 \mathrm{~K}$ Sty array. Genes showing both upregulated expression and copy number gains in cases involving recurrence were extracted as candidate biomarkers. The protein expression of the candidate gene was assessed using immunohistochemical staining of tissue from 161 patients. The relationship between protein expression and clinicopathological features was also examined. We identified 9 candidate genes related to recurrence of stage II and III CRC, whose mRNA expression was significantly higher in CRC than in normal tissue. Of these proteins, the S100 calcium-binding protein A2 (S100A2) has been observed in several human cancers. S100A2 protein overexpression in CRC cells was associated with significantly worse overall survival and relapse-free survival, indicating that S100A2 is an independent risk factor for stage II and III CRC recurrence. S100A2 overexpression in cancer cells could be a biomarker of poor prognosis in stage II and III CRC recurrence and a target for treatment of this disease.
\end{abstract}

\section{Introduction}

Colorectal cancer (CRC) is one of the most prevalent cancers in the world (1). It is the second leading cause of cancerrelated mortality worldwide. In Japan, the incidence of CRC has doubled over the past 20 years such that CRC is now the second most deadly neoplastic disease $(2,3)$.

Correspondence to: Dr Toshiaki Ishikawa, Department of Surgical Oncology, Tokyo Medical and Dental University Graduate School of Medicine, 1-5-45 Yushima, Bunkyo-ku, Tokyo 113-8510, Japan

E-mail: ishi.srg2@tmd.ac.jp

Key words: S100A2, colorectal cancer, biomarker, microarray, gene expression analysis, DNA copy number analysis
Surgery is still the most effective treatment for CRC. Among the patients that undergo curative surgery, some develop local recurrence or distant metastases that lead to shorter survival times (4). Distant metastasis has a critical influence on the prognosis of CRC. Clinicopathological indicators such as the TNM classification proposed by the International Union Against Cancer (UICC) remain the indicator of prognosis and provide the basis for therapeutic decision making. However, the current TNM classification system is limited in that it cannot predict prognosis for individual patients (5). In order to develop personalized therapeutic regimens, it is therefore critical that novel genes involved in distant metastasis are identified that can serve as prognostic biomarkers (6). Microarray is a particularly powerful tool for identifying potential biomarker genes for use in cancer prognosis (7-9). Using microarray analysis it is now possible to investigate several thousand cancer-related or cancer-specific genes at once.

Chromosomal structural alterations play an important role in cancer development. In CRC, copy number aberrations (CNAs), including gains on chromosomes 7, 8, 13 and 20, and losses on chromosomes $1 \mathrm{p}, 8 \mathrm{p}, 17 \mathrm{p}$ and 18 , are frequently observed (10-13). Some of these CNAs are related to metastasis of CRC and can thus be used in prognosis. The single nucleotide polymorphism microarray (SNP array) analysis has become a useful tool for examining CNAs, permitting highly accurate exploration of thousands of genetic markers in a single study (14).

Studies of the relationship between chromosomal aberrations and gene expression in cancers, including CRC, have shown that CNAs directly influence gene expression (15-19). Several groups have therefore suggested that integrating gene expression analysis with genomic profiling represents an efficient approach for the discovery of cancer-related genes (20-22). Genes that show a strong positive correlation between expression and copy number may play an important role in cancer progression. In this study, we therefore integrated gene expression and copy number analyses to identify novel genes associated with the distant metastasis of CRC. We focused on the genes that are overexpressed and have an amplified copy number in cases of distant metastasis because such characteristics indicate that these genes have the potential to serve as useful therapeutic targets or clinical biomarkers. 
Using the aforementioned comprehensive analysis, we identified S100 calcium-binding protein A2 (S100A2) as a gene involved in the distant metastasis of stage II and III CRC. It has been suggested that S100A2 plays an important role in cell cycle progression, and overexpression of S100A2 has been reported in several cancers (23-28). This is the first study to demonstrate the prognostic significance of S100A2 expression in CRC, using integrated copy number and gene expression analyses of clinical tissue samples.

\section{Patients and methods}

Patients. Primary tumors from 278 patients who underwent curative surgery for stage II and III CRC between 2002 and 2009 at the Tokyo Medical and Dental University Hospital (Tokyo, Japan) were studied. Written informed consent was obtained from all the patients, and the study was approved by the ethics committee of Tokyo Medical and Dental University, and all the following procedures were performed strictly in accordance with the ethical standards established by this committee. Clinical data were obtained from the medical records of each patient, and histopathological evaluations were assessed by reference to the criteria of the TNM-system of the UICC, 7th edition. A total of 125 patients were assigned to the comprehensive analyses for extraction of candidate genes. All of the patients were assigned to the gene expression and the CNA study, including 66 patients with stage II and 59 patients with stage III disease. The median follow-up time for these patients was 62 months (range, 1-76 months). Quantitative reverse transcription polymerase chain reaction (RT-PCR) assays were performed for validation using samples from 50 stage II and III CRC patients, including 24 patients with stage II and 26 patients with stage III disease. The median follow-up time for these patients was 61 months (range, 7-96 months). Furthermore, 161 patients, including patients subjected to RT-PCR validation, were analyzed using immunohistochemistry (IHC). The IHC study included 80 patients with stage II and 81 patients with stage III disease. The median follow-up time for these patients was 86 months (range, 1-96 months). The patients enrolled in the comprehensive analyses were excluded from these validation studies.

DNA extraction. After resection, cancer tissues were immediately embedded in Tissue-Tek OCT compound medium (Sakura Finetek Japan, Tokyo, Japan). Serial frozen sections of 9-mm in thickness were mounted onto a 90 FOIL-SL25 foilcoated glass slide (Leica Microsystems, Wetzlar, Germany). Laser capture microdissection (LCM) was performed using an Application Solutions LCM System (Leica Microsystems). Tumor DNA was extracted and purified using a QIAamp DNA micro kit (Qiagen, Hilden, Germany) according to the manufacturer's instructions. Non-neoplastic tissues were homogenized in microtubes, and DNA was extracted and purified from these tissues using a QIAamp DNA mini kit (Qiagen) according to the manufacturer's instructions.

CNA analysis. Copy number analysis was performed using a GeneChip ${ }^{\circledR}$ Human Mapping 250K Sty array (Affymetrix, Santa Clara, CA, USA) in strict adherence to the assay manual. Genomic DNA was digested using the enzyme StyI, and a Sty1 adaptor was used prior to the PCR reaction. Amplicons were fragmented after purification and then labeled. After hybridization, the microarrays were transferred to a totally automated GeneChip ${ }^{\circledR}$ Fluidics Station 450 (Affymetrix) for the washing and staining steps. After fluorescence staining, microarray images were scanned using a GeneChip ${ }^{\circledR}$ Scanner $30007 \mathrm{G}$ (Affymetrix). The microarray data from the scanner were used for copy number analysis with the Chromosome Copy Number Analysis Tool (Affymetrix). Data were analyzed using R statistical software (version 2.12.1; http://www.r-project.org/).

RNA extraction. Cancer cells were microdissected using LCM. Total RNA was extracted from cancer cells and purified using an RNeasy micro kit (Qiagen) with on-column DNase digestion, according to the manufacturer's instructions. Total RNA collected from bulk samples of cancer tissues and adjacent non-neoplastic tissues was extracted and purified using an RNeasy mini kit (Qiagen) with on-column DNase digestion, according to the manufacturer's instructions. The integrity of the total RNA was assessed using an Agilent 2100 BioAnalyzer (Agilent Technologies, Palo Alto, CA, USA). Samples with an RNA integrity number $>5.0$ were used for the rest of the experiments.

Gene expression analysis. Complementary RNA was prepared from total RNA using two-cycle target labeling and a control reagents kit (Affymetrix). The experiment was performed using the GeneChip ${ }^{\circledR}$ Human Genome U133 Plus 2.0 Array (Affymetrix), according to the manufacturer's instructions. Statistical analyses of microarray data were normalized using the robust multi-array average method with $\mathrm{R}$ statistical software (version 2.12.1; http://www.r-project.org/) together with the BioConductor package (http://www.bioconductor.org/).

Extraction of candidate genes. We defined patients with metastatic recurrence of stage II and III CRC as the recurrence group, and patients without any recurrence as the non-recurrence group. Local recurrence and lymph node recurrence were excluded from the recurrence group. The CNA data and the gene expression data were analyzed and compared between the 2 groups to identify genes involved in the metastatic recurrence of stage II and III CRC.

Data regarding genes which showed a copy number gain in the recurrence group were extracted using Fisher's exact test $(\mathrm{P}<0.01)$. Data regarding genes that were significantly upregulated in the recurrence group were extracted using the Wilcoxon exact rank sum test $(\mathrm{P}<0.01)$. Among the genes that were common to both groups, those that were overexpressed (fold change $>1.5$ ) in the recurrence group were selected as candidates for further analysis.

The gene expression data and DNA copy number data were deposited in the Gene Expression Omnibus (GEO) under accession IDs GSE64256, GSE64257 and GSE64258.

Quantitative RT-PCR. Total RNA collected from bulk samples of cancer tissues and adjacent non-neoplastic tissues was reverse-transcribed into cDNA using a High Capacity cDNA Reverse Transcription kit (Applied Biosytems, Foster City, CA, USA) according to the manufacturer's instructions. A TaqMan ${ }^{\circledR}$ gene expression assay (Applied Biosystems; S100A2; 


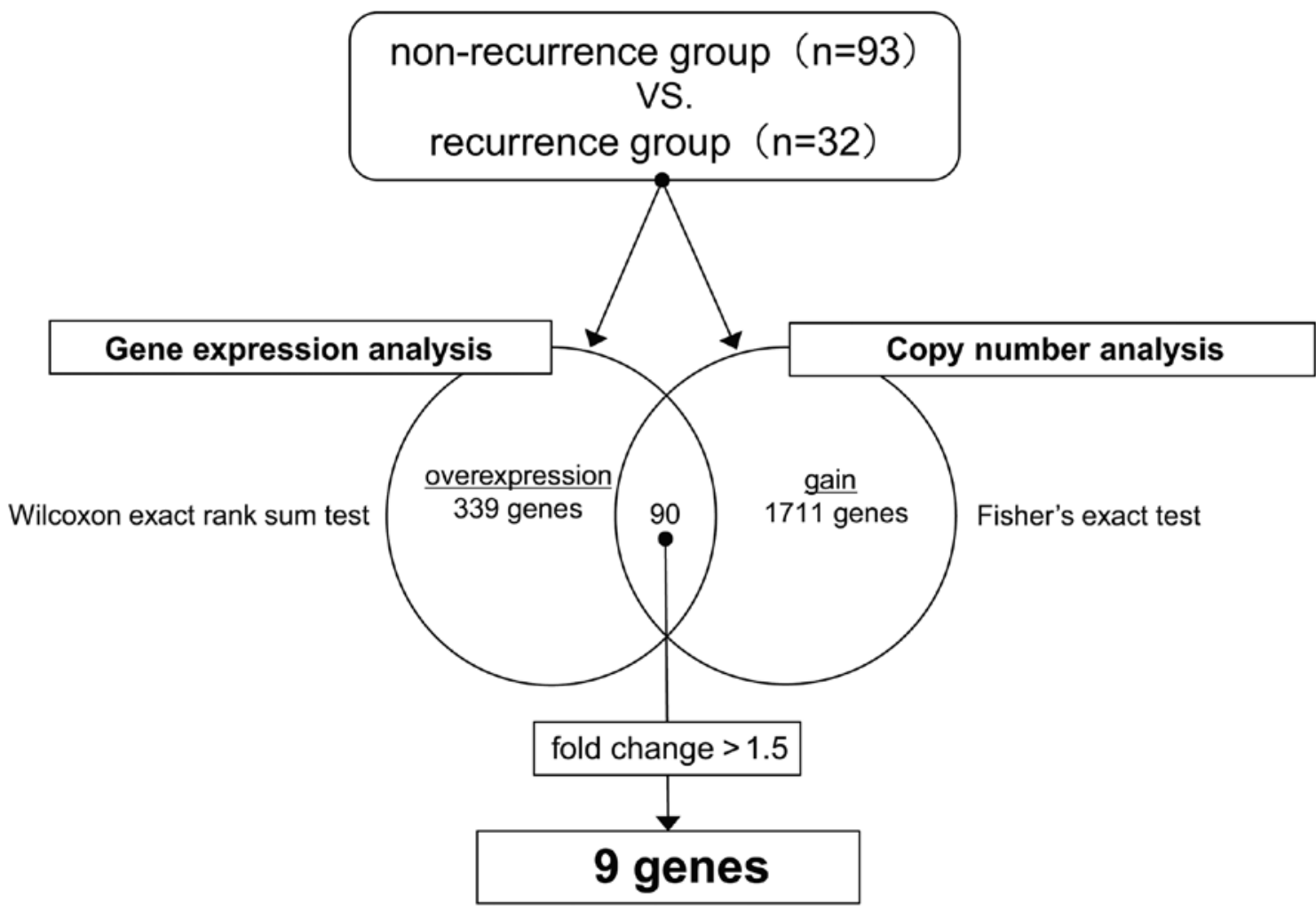

Figure 1. Identification of candidate genes. The scheme for identification of candidate genes related to recurrence in patients with stage II and III colorectal cancer is shown. A total of 339 genes were extracted from the gene expression analysis, and 1,711 genes were extracted from the CNA analysis. Among the 90 genes extracted from both analyses, 9 genes with a fold change in expression of $>1.5$ were selected as candidates for further analysis.

Hs00195582_m1, $\beta$-actin; Hs99999903_m1) was used to investigate the expression of S100A2, and $\beta$-actin was used as an internal control. The PCR reaction was carried out using TaqMan ${ }^{\circledR}$ Universal PCR Master Mix (Applied Biosystems). The thermal cycling conditions were as follows: $50^{\circ} \mathrm{C}$ for $2 \mathrm{~min}, 95^{\circ} \mathrm{C}$ for $10 \mathrm{~min}$, and 40 cycles of denaturation at $95^{\circ} \mathrm{C}$ for $15 \mathrm{sec}$ and annealing at $60^{\circ} \mathrm{C}$ for $1 \mathrm{~min}$. All calculated concentrations of target genes were normalized by the amount of the endogenous reference using the comparative $\mathrm{Ct}$ method for relative quantification with Relative Quantification Study Software (7300 Sequence Detection System version 1.2.1, Applied Biosystems).

Immunohistochemistry. IHC analyses of S100A2 were conducted on formalin-fixed paraffin-embedded tissue blocks from each patient. For S100A2 staining, antigen retrieval by autoclave treatment was carried out for $15 \mathrm{~min}$ in $1 \mathrm{X} \mathrm{TE}$ (1X Tris-EDTA, $\mathrm{pH} 8.0$ ) at $121^{\circ} \mathrm{C}$ after deparaffinization in xylene and rehydration through a series of incubations in graded concentrations of ethanol. The slides were then incubated in a solution of $3 \%$ hydrogen peroxide in $100 \%$ methanol for $15 \mathrm{~min}$ at room temperature in order to quench endogenous peroxidase activity. Subsequently, the slides were incubated with mouse monoclonal antibody against S100A2 (Sigma-Aldrich), at a 1:50 dilution, for $30 \mathrm{~min}$ at room temperature. The slides were then incubated with peroxidase-labeled antibody [Histofine Simple Stain Max PO (MULTI; Nichirei Bioscience)] for $30 \mathrm{~min}$ at room temperature. Peroxidase activity was detected with DAB Solution (Histofine Simple
Stain DAB Solution; Nichirei BioScience). Finally, the slides were counterstained with $1 \%$ Mayer's hematoxylin.

All the sections were divided into four stages (negative, weak, moderate, or strong) by staining intensity. Expression was graded by two independent observers who were blinded to the patient information.

Statistical analysis of S100A2 expression. Statistical analyses of S100A2 expression were carried out using SPSS (version 17.0, SPSS Inc, Chicago, IL, USA) software for Windows. To estimate the significance of differences between groups, Wilcoxon signed-rank, Mann-Whitney U, and $\mathrm{C}^{2}$ tests were used where appropriate. Survival curves were estimated using the KaplanMeier method, and curves were compared using the log-rank test. Survival times were determined from the date of surgery. Prognostic factors were examined with univariate and multivariate analyses using the Cox proportional hazards model. A P-value $<0.05$ was considered statistically significant.

\section{Results}

Gene expression and copynumber analyses. In the copy number and gene expression analyses, 9 genes (S100A2, PROX1, TCN1, PROM1, CHRM3, ZNF678, CREB5, PPARGC1A, and ATF6) were identified that fulfilled the specified criteria. Of the 9 genes with both elevated copy number and expression, the expression was upregulated with a fold change $>1.5$ (Fig. 1). Only S100A2 and TCN1 of these genes have been shown to be associated with cancer. Overexpression of S100A2 has been 

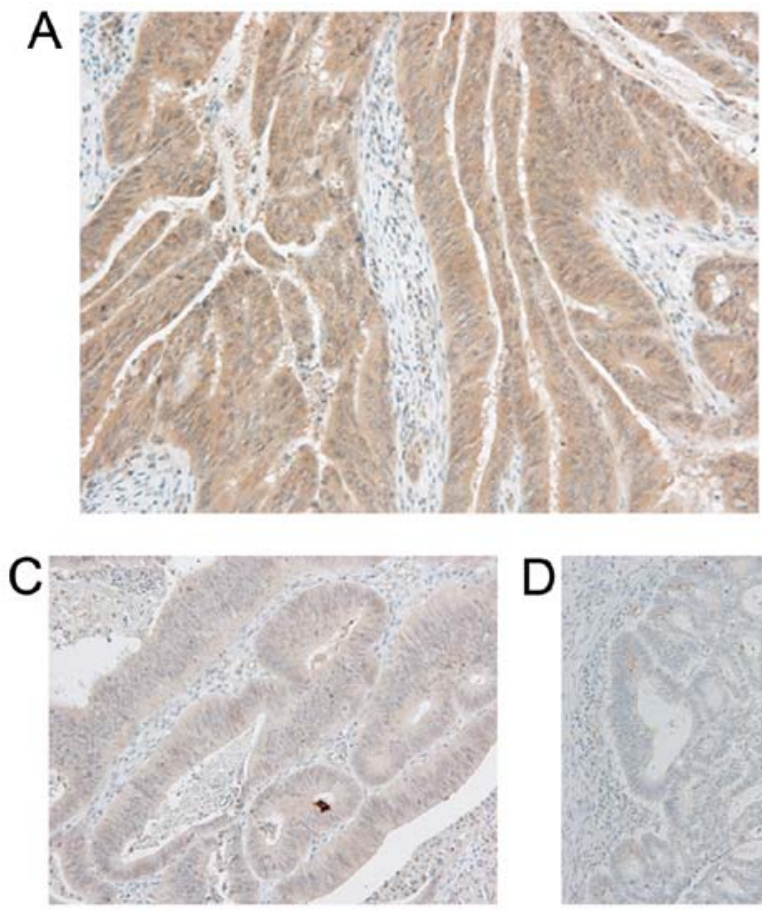

D
B
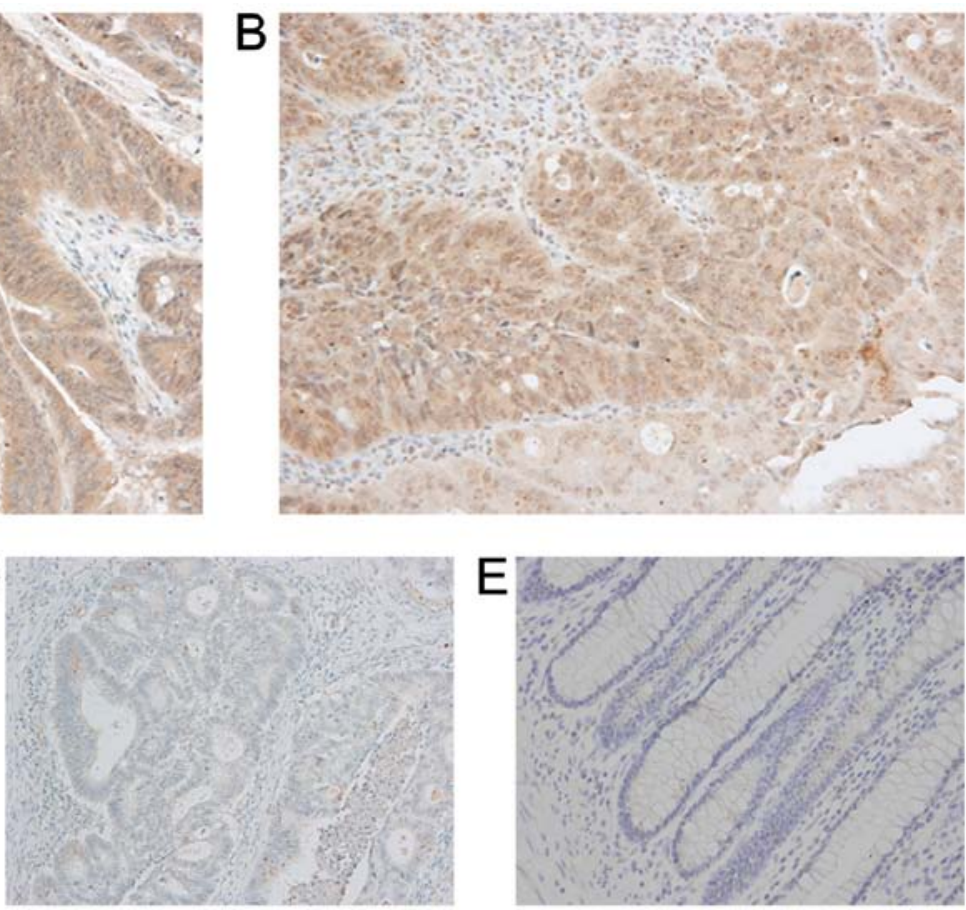

Figure 2. Immunohistochemical staining of S100A2 in colorectal carcinoma tissue. Representative images of the invasive tumor front of colorectal carcinoma tissue showing strong (A), moderate (B), weak (C), negative (D) normal tissue (E) immunohistochemical staining for S100A2.

A Relapse free survival (RFS) (Stage II - III)

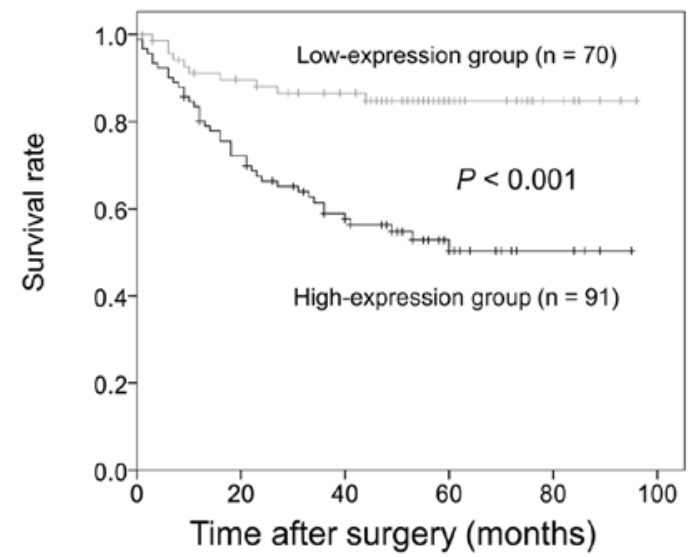

B Overall survival (OS) (Stage II - III)

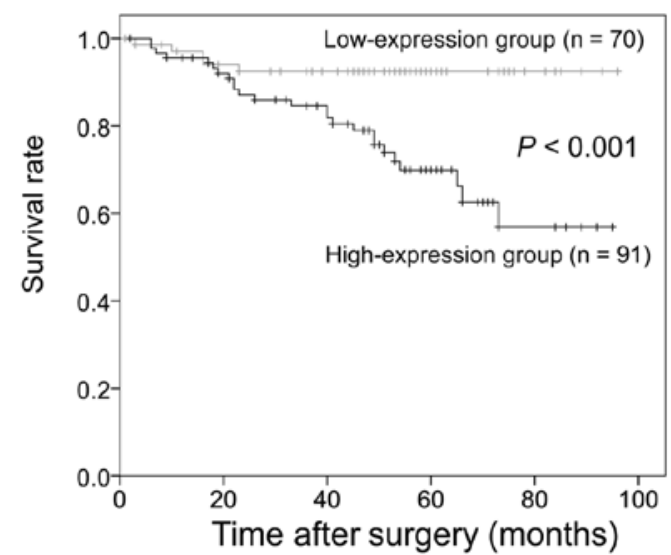

C

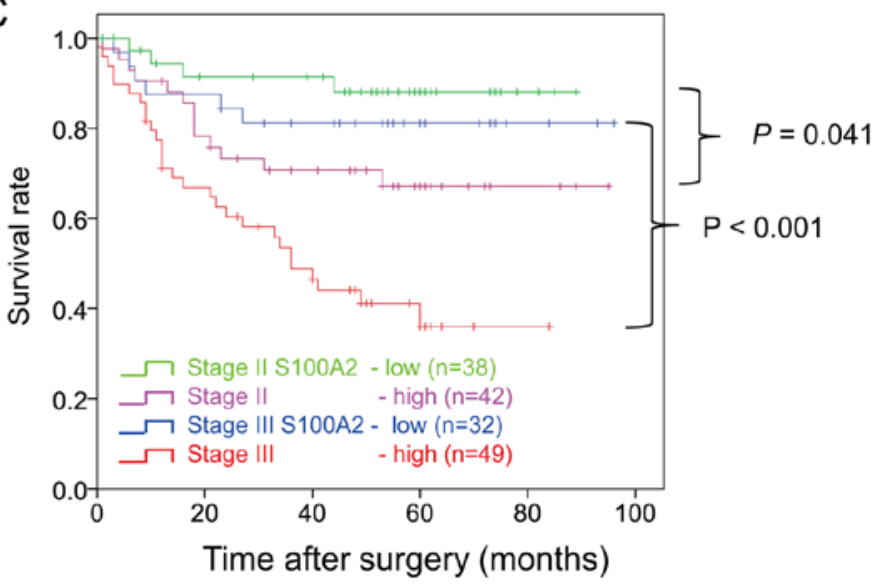

Log-rank test

Figure 3. Association of S100A2 expression levels with survival of stage II and III colorectal cancer patients. (A and B) Stage II and III colorectal cancer patients $(\mathrm{n}=161)$ were divided into S100A2 high- and low-expressing groups that were analyzed for (A) relapse-free survival (RFS) and (B) overall survival (OS), using Kaplan-Meier curves. (C) Kaplan-Meier curves show RFS stratified by TNM-7th stage and S100A2 expression group. RFS curves were significantly separated by S100A2 expression group in both stage II and III patients. 
reported to occur in several cancers, although it has not been reported in relation to prognosis in CRC (23-29). We therefore focused on S100A2 in the subsequent analyses.

S100A2 mRNA and protein expression. Quantitative RT-PCR analysis of stage II and III CRC tissue from 50 patients showed that expression of S100A2 mRNA is significantly higher in cancerous tissue than in neighboring non-neoplastic tissue (data not shown). The cellular localization of the S100A2 protein was investigated using cancer tissue from the same $50 \mathrm{CRC}$ patients that were analyzed using RT-PCR. IHC indicated that the S100A2 protein is localized in the cytoplasm of CRC cells, whereas staining for the S100A2 protein in normal epithelial cells adjacent to the cancer cells was negative or weak. There was no difference in staining intensity of the invasive tumor front and the marginal tissue of the tumor. As a result of these data, we then estimated the extent and intensity of S100A2 staining in sections containing the area of infiltration in stage II and III CRC tissue samples from 161 patients. As shown in Fig. 2, in the cytoplasm of cancer cells, staining was observed in three patterns, strong (Fig. 2A), moderate (Fig. 2B) and weak (Fig. 2C).

Relationship between the expression of S100A2 and patient characteristics. For statistical evaluation purposes, the 161 samples that underwent IHC were divided into 2 groups: a high-expression group (strong staining spread of $>10 \%$ or moderate staining spread of $>70 \%, \mathrm{n}=91$ ) and a low-expression group (the others, $\mathrm{n}=70$ ).

The correlation between S100A2 expression and various clinicopathological factors in 161 patients with stage II or III $\mathrm{CRC}$ is shown in Table I. Location (rectum; $\mathrm{P}=0.001$ ), venous invasion (positive; $\mathrm{P}=0.011$ ), and the presence or absence of recurrence (recurrence group; $\mathrm{P}<0.001$ ) were significantly associated with overexpression of S100A2.

S100A2 expression and prognosis of stage II and III patients. The relapse-free survival (RFS) rate was significantly lower $(\mathrm{P}<0.001)$ in the $\mathrm{S} 100 \mathrm{~A} 2$ high-expression group than in the low-expression group (Fig. 3A). Univariate analysis indicated that gender $(\mathrm{P}=0.024)$, histology $(\mathrm{P}=0.022)$, location $(\mathrm{P}=0.003)$, lymphatic invasion $(\mathrm{P}=0.024)$, lymph node metastasis $(\mathrm{P}=0.007)$, CEA level $(5.0 \mathrm{ng} / \mathrm{ml}$ or higher; $\mathrm{P}=0.003)$, and $\mathrm{S} 100 \mathrm{~A} 2$ expression $(\mathrm{P}<0.001)$ were significantly associated with RFS. Multivariate analysis indicated that overexpression of S100A2 is a significant prognostic factor of RFS for Stage II or III CRC patients $(\mathrm{P}=0.007$; relative risk $(\mathrm{RR})=2.726$; 95\% confidence interval, 1318-5.638) (Table II).

Likewise, the overall survival (OS) rate was significantly lower $(\mathrm{P}<0.001)$ in the $\mathrm{S} 100 \mathrm{~A} 2$ high-expression group than in the low-expression group (Fig. 3B). Univariate analysis indicated that gender $(\mathrm{P}=0.007)$, histology $(\mathrm{P}=0.005)$, location $(\mathrm{P}=0.009)$, tumor depth $(\mathrm{P}=0.007)$, lymphatic invasion $(\mathrm{P}=0.013)$, lymph node metastasis $(\mathrm{P}=0.024)$, CEA level $(\mathrm{P}=0.004)$, and $\mathrm{S} 100 \mathrm{~A} 2$ expression $(\mathrm{P}<0.001)$ were significantly associated with OS. Multivariate analysis indicated that S100A2 overexpression is an independent and significant prognostic factor of OS for patients with stage II or III CRC $(\mathrm{P}=0.008 ; \mathrm{RR}=3.941 ; 95 \%$ confidence interval, 1.434-10.830) (Table III)
Table I. Relationship between clinicopathologic variables and S100A2 expression in patients with stage II-III colorectal cancer.

\begin{tabular}{|c|c|c|c|}
\hline \multirow[b]{2}{*}{ Variables } & \multicolumn{2}{|c|}{ S100A2 expression } & \multirow[b]{2}{*}{ P-value } \\
\hline & Low $(n=70)$ & High $(n=91)$ & \\
\hline Age (median), years & $31-92(67)$ & $20-86(68)$ & 0.63 \\
\hline Gender & & & 0.555 \\
\hline Male & 43 & 60 & \\
\hline Female & 27 & 31 & \\
\hline Histology & & & 0.301 \\
\hline Well & 27 & 28 & \\
\hline $\begin{array}{l}\text { Moderate, poor } \\
\text { and others }\end{array}$ & 43 & 63 & \\
\hline Location & & & $\underline{0.001}$ \\
\hline Colon & 53 & 46 & \\
\hline Rectum & 17 & 45 & \\
\hline Depth & & & 0.933 \\
\hline T1/T2/T3 & 42 & 54 & \\
\hline $\mathrm{T} 4$ & 28 & 37 & \\
\hline Lymphatic invasion & & & 0.139 \\
\hline Negative & 20 & 17 & \\
\hline Positive & 50 & 74 & \\
\hline Venous invasion & & & $\underline{0.011}$ \\
\hline Negative & 10 & 3 & \\
\hline Positive & 60 & 88 & \\
\hline $\begin{array}{l}\text { Lymph node } \\
\text { metastasis }\end{array}$ & & & 0.306 \\
\hline Negative & 38 & 42 & \\
\hline Positive & 32 & 49 & \\
\hline CEA (ng/ml) & & & 0.201 \\
\hline$<5$ & 46 & 50 & \\
\hline$\geq 5$ & 20 & 38 & \\
\hline Recurrence & & & $\leq 0.001$ \\
\hline Non-rec & 61 & 56 & \\
\hline $\operatorname{Rec}$ & 9 & 35 & \\
\hline
\end{tabular}

P-values less than 0.05 are underlined.

Fig. 3C shows RFS curves stratified by TNM-7th stage and S100A2 expression level group. RFS curves were significantly separated by S100A2 expression level group in both stage II and III patients. RFS was significantly worse in the S100A2 high expression group than in the S100A2 low expression group in stage II $(\mathrm{P}=0.041)$ as well as in stage III $(\mathrm{P}<0.001)$ patients.

\section{Discussion}

This study is the first to demonstrate the prognostic significance of intratumoral S100A2 expression in clinical tissue samples of CRC. S100A2 was identified as a recurrence-related 
Table II. Univariate and multivariate analysis of clinicopathologic factors affecting relapse-free survival in patients with stage II-III colorectal cancer.

\begin{tabular}{lccc}
\hline \multirow{3}{*}{ Variables } & & \multicolumn{2}{c}{ Multivariate analysis } \\
\cline { 3 - 4 } & No. of & Univariate \\
patients & $\begin{array}{c}\text { analysis } \\
\text { P-value }\end{array}$ & $\begin{array}{c}\text { Relative risk } \\
\left(\begin{array}{l}\text { 95\% confidence } \\
\text { interval) }\end{array}\right.\end{array}$ \\
\hline
\end{tabular}

\begin{tabular}{lrl}
\hline Age & & 0.705 \\
$\leq 65$ & 81 & \\
$>65$ & 80 & \\
Gender & & 0.024 \\
Male & 103 &
\end{tabular}

Male $\quad 103$

Female $\quad 58$

Histology

0.022

Well 55

Moderate, 106

poor and

others

Location

Colon

0.003

Rectum

99

62

Depth

T1/T2/T3

$\mathrm{T} 4$

96

0.091

65

Lymphatic

0.024

invasion

Negative

37

Positive

124

Venous

invasion

Negative 13

Positive 148

Lymph node

0.007

metastasis

Negative $\quad 80$

Positive 81

CEA (ng/ml)

$\begin{array}{ll}<5 & 96 \\ >5 & 58\end{array}$

S100A2

expression

Low $\quad 70$

High

70

91

0.149

0.078

0.332

0.195

0.335
Table III. Univariate and multivariate analysis of clinicopathologic factors affecting overall survival in patients with stage II-III colorectal cancer.

\begin{tabular}{cccc}
\hline \multirow{3}{*}{ Variables } & & Multivariate analysis \\
\cline { 3 - 4 } & No. of & Univariate \\
patients & analysis & Relative risk & P-value \\
& & P-value & $(95 \%$ confidence \\
& & interval $)$ \\
\hline
\end{tabular}

\begin{tabular}{lll}
\hline Age & & 0.061 \\
$\leq 65$ & 81 & \\
$>65$ & 80 &
\end{tabular}

Gender

0.007

0.058

Male $\quad 103$

Female $\quad 58$

Histology

0.005

0.115

Well $\quad 55$

Moderate, 106

poor and

others

Location

Colon

0.009

0.111

Rectum

99

62

Depth

0.007

T1/T2/T3

$\mathrm{T} 4$

96

65

Lymphatic

0.013

invasion

Negative 37

Positive

124

Venous

invasion

Negative 13

Positive 148

Lymph node

0.024

0.613

metastasis

Negative

80

Positive

CEA (ng/ml)

81

$<5$

0.004

0.533

$\geq 5$

96

58

S100A2

expression

Low $\quad 70$

$<0.001$

3.941

$\underline{0.008}$

High

91

P-value less than 0.05 in multivariate analysis is underlined.

gene in the combined analysis of gene expression and copy number, and high S100A2 expression was an independent and

significant prognostic factor of distant recurrence after curative surgery for stage II or III CRC. 
The S100A2 gene is located on chromosome 1q.21. The human S100A2 is a member of the S100 family. It has been suggested that this family promotes tumor progression and metastasis by regulating the cell cycle, motility, and invasion in many human neoplasms (30-34). S100A2 is an EF-hand calcium-binding protein that regulates protein phosphorylation, cytoskeletal components, and calcium homeostasis both inside and outside of cells $(30,35)$. The S100A2 protein, which is found in the cytoplasm and nucleus of epithelial cells including those in the esophagus and colon, is involved in TGF- $\beta$ signaling $(36,37)$. It has also been suggested to play a role in the cell cycle regulation of p53. S100A2 protein overexpression has been reported in lung cancer, brain cancer, and several types of gastroenterological cancers such as pancreatic and esophageal cancers (35). The S100A2 protein is reported to be involved in the chemotactic activity of tumor cells in colon cancer $(37,38)$. In addition, S100A2 knockdown has been reported to reduce TGF- $\beta$-induced cellular chemotaxis (37). In the present study, high expression of S100A2 was significantly related with recurrence with distant metastasis. Our results support the idea that S100A2 might play an important role in distant metastasis of CRC. Further studies are warranted to investigate the roles and functions of S100A2 in CRC.

At present, recurrence risk and prognosis are predicted largely based on pathological tumor staging (TNM classification). The usefulness of postoperative adjuvant chemotherapy for stage II CRC has not been established yet, and it is recommended that determination of whether or not to use adjuvant chemotherapy should be based on the recurrence risk predicted for each patient. Major western guidelines, such as the National Comprehensive Cancer Network of Clinical Practice Guidelines in Oncology, recommend adjuvant chemotherapy when patients have risk factors including T4 lesions, less than 12 lymph nodes examined, perforation, poorly differentiated histology, and lymphovascular involvement. Our results suggested that stage II CRC patients with high S100A2 expression might be candidates for adjuvant chemotherapy as high-risk patients of distant recurrence. For stage III CRC, postoperative chemotherapy is recommended without exception. However, when stage III is further divided into IIIA, IIIB, and IIIC according to the TNM-7th classification and each sub-stage is considered separately, it has been reported that an additive effect of oxaliplatin cannot be anticipated in stage IIIA patients, and that stratification of the recurrence risk is important for stage III colon cancer as is the case for stage II CRC $(39,40)$. Our study suggests that stage III CRC patients with high S100A2 expression may require strong adjuvant chemotherapy. Validation of the usefulness of risk-guided treatment is important in postoperative chemotherapy for stage II and III CRC and further clinical studies need to be conducted.

In conclusion, this study demonstrated that S100A was expressed at a significantly increased level in the CRC recurrence group. In our screen, we focused on highly expressed genes, because we intended to use the identified gene, S100A2, as a blood biomarker in actual clinical practice. The results of our study suggest the potential of the S100A protein as a recurrence-predicting factor and a target for moleculartargeted drugs for CRC.

\section{Acknowledgements}

The authors thank Y. Takagi and M. Itoda for excellent technical assistance.

\section{References}

1. Ricchi P,Zarrilli R, Di Palma A and Acquaviva AM: Nonsteroidal anti-inflammatory drugs in colorectal cancer: From prevention to therapy. Br J Cancer 88: 803-807, 2003.

2. Tsukuma H, Ajiki W and Oshima A: Cancer incidence in Japan. Gan To Kagaku Ryoho 31: 840-846, 2004 (In Japanese).

3. Matsuda T, Marugame T, Kamo K, Katanoda K, Ajiki W and Sobue T; Japan Cancer Surveillance Research Group: Cancer incidence and incidence rates in Japan in 2004: Based on data from 14 population-based cancer registries in the Monitoring of Cancer Incidence in Japan (MCIJ) Project. Jpn J Clin Oncol 40: 1192-1200, 2010.

4. Kobayashi H, Mochizuki H, Sugihara K, Morita T, Kotake K, Teramoto T, Kameoka S, Saito Y, Takahashi K, Hase K, et al: Characteristics of recurrence and surveillance tools after curative resection for colorectal cancer: A multicenter study. Surgery 141: 67-75, 2007.

5. Weitz J, Koch M, Debus J, Höhler T, Galle PR and Büchler MW: Colorectal cancer. Lancet 365: 153-165, 2005.

6. Ross JS, Torres-Mora J, Wagle N, Jennings TA and Jones DM: Biomarker-based prediction of response to therapy for colorectal cancer: Current perspective. Am J Clin Pathol 134: 478-490, 2010.

7. Wang Y, Jatkoe T, Zhang Y, Mutch MG, Talantov D, Jiang J, McLeod HL and Atkins D: Gene expression profiles and molecular markers to predict recurrence of Dukes' B colon cancer. J Clin Oncol 22: 1564-1571, 2004.

8. Shih W, Chetty R and Tsao MS: Expression profiling by microarrays in colorectal cancer (Review). Oncol Rep 13: 517-524, 2005.

9. Nannini M, Pantaleo MA, Maleddu A, Astolfi A, Formica S and Biasco G: Gene expression profiling in colorectal cancer using microarray technologies: Results and perspectives. Cancer Treat Rev 35: 201-209, 2009.

10. Aragane H, Sakakura C, Nakanishi M, Yasuoka R, Fujita Y, Taniguchi H, Hagiwara A, Yamaguchi T, Abe T, Inazawa J, et al: Chromosomal aberrations in colorectal cancers and liver metastases analyzed by comparative genomic hybridization. Int J Cancer 94: 623-629, 2001.

11. Kurashina K, Yamashita Y, Ueno T, Koinuma K, Ohashi J, Horie H, Miyakura Y, Hamada T, Haruta H, Hatanaka H, et al: Chromosome copy number analysis in screening for prognosisrelated genomic regions in colorectal carcinoma. Cancer Sci 99: 1835-1840, 2008.

12. Nakao M, Kawauchi S, Furuya T, Uchiyama T, Adachi J, Okada T, Ikemoto K, Oga A and Sasaki K: Identification of DNA copy number aberrations associated with metastases of colorectal cancer using array CGH profiles. Cancer Genet Cytogenet 188: 70-76, 2009.

13. Yamamoto S, Midorikawa Y, Morikawa T, Nishimura Y, Sakamoto H,Ishikawa S, Akagi K and Aburatani H: Identification of chromosomal aberrations of metastatic potential in colorectal carcinoma. Genes Chromosomes Cancer 49: 487-496, 2010.

14. Yau C and Holmes CC: CNV discovery using SNP genotyping arrays. Cytogenet Genome Res 123: 307-312, 2008.

15. Phillips JL, Hayward SW, Wang Y, Vasselli J, Pavlovich C, Padilla-Nash H, Pezullo JR, Ghadimi BM, Grossfeld GD, Rivera A, et al: The consequences of chromosomal aneuploidy on gene expression profiles in a cell line model for prostate carcinogenesis. Cancer Res 61: 8143-8149, 2001.

16. Hyman E, Kauraniemi P, Hautaniemi S, Wolf M, Mousses S, Rozenblum E, Ringnér M, Sauter G, Monni O, Elkahloun A, et al: Impact of DNA amplification on gene expression patterns in breast cancer. Cancer Res 62: 6240-6245, 2002.

17. Pollack JR, Sørlie T, Perou CM, Rees CA, Jeffrey SS, Lonning PE, Tibshirani R, Botstein D, Børresen-Dale AL and Brown PO: Microarray analysis reveals a major direct role of DNA copy number alteration in the transcriptional program of human breast tumors. Proc Natl Acad Sci USA 99: 12963-12968, 2002.

18. Tsafrir D, Bacolod M, Selvanayagam Z, Tsafrir I, Shia J, Zeng Z, Liu H, Krier C, Stengel RF, Barany F, et al: Relationship of gene expression and chromosomal abnormalities in colorectal cancer. Cancer Res 66: 2129-2137, 2006. 
19. Ramakrishna M, Williams LH, Boyle SE, Bearfoot JL, Sridhar A, Speed TP, Gorringe KL and Campbell IG: Identification of candidate growth promoting genes in ovarian cancer through integrated copy number and expression analysis. PLoS One 5: e9983, 2010.

20. Nigro JM, Misra A, Zhang L, Smirnov I, Colman H, Griffin C, Ozburn N, Chen M, Pan E, Koul D, et al: Integrated arraycomparative genomic hybridization and expression array profiles identify clinically relevant molecular subtypes of glioblastoma. Cancer Res 65: 1678-1686, 2005.

21. Cardoso J, Boer J, Morreau H and Fodde R: Expression and genomic profiling of colorectal cancer. Biochim Biophys Acta 1775: 103-137, 2007.

22. Yoshida T, Kobayashi T, Itoda M, Muto T, Miyaguchi $\mathrm{K}$, Mogushi K, Shoji S, Shimokawa K, Iida S, Uetake H, et al: Clinical omics analysis of colorectal cancer incorporating copy number aberrations and gene expression data. Cancer Inform 9 : 147-161, 2010.

23. Pedrocchi M, Schäfer BW, Mueller H, Eppenberger U and Heizmann CW: Expression of $\mathrm{Ca}(2+)$-binding proteins of the S100 family in malignant human breast-cancer cell lines and biopsy samples. Int J Cancer 57: 684-690, 1994.

24. Böni R, Heizmann CW, Doguoglu A, Ilg EC, Schäfer BW, Dummer R and Burg G: $\mathrm{Ca}(2+)$-binding proteins S100A6 and S100B in primary cutaneous melanoma. J Cutan Pathol 24: 76-80, 1997.

25. Lauriola L, Michetti F, Maggiano N, Galli J, Cadoni G, Schäfer BW, Heizmann CW and Ranelletti FO: Prognostic significance of the $\mathrm{Ca}(2+)$ binding protein S100A2 in laryngeal squamous-cell carcinoma. Int J Cancer 89: 345-349, 2000.

26. Feng G, Xu X, Youssef EM and Lotan R: Diminished expression of S100A2, a putative tumor suppressor, at early stage of human lung carcinogenesis. Cancer Res 61: 7999-8004, 2001.

27. Gupta S, Hussain T, MacLennan GT, Fu P, Patel J and Mukhtar H: Differential expression of S100A2 and S100A4 during progression of human prostate adenocarcinoma. J Clin Oncol 21: 106-112, 2003

28. Tsai ST, Jin YT, Tsai WC, Wang ST, Lin YC, Chang MT and Wu LW: S100A2, a potential marker for early recurrence in early-stage oral cancer. Oral Oncol 41: 349-357, 2005.

29. Simonsen K, Rode A, Nicoll A, Villadsen G, Espelund U, Lim L, Angus P, Arachchi N, Vilstrup H, Nexo E, et al: Vitamin B12 and its binding proteins in hepatocellular carcinoma and chronic liver diseases. Scand J Gastroenterol 49: 1096-1102, 2014.
30. Salama I, Malone PS, Mihaimeed F and Jones JL: A review of the S100 proteins in cancer. Eur J Surg Oncol 34: 357-364, 2008.

31. Haase-Kohn C, Wolf S, Lenk J and Pietzsch J: Copper-mediated cross-linking of S100A4, but not of S100A2, results in proinflammatory effects in melanoma cells. Biochem Biophys Res Commun 413: 494-498, 2011

32. Jamieson NB, Carter CR, McKay CJ and Oien KA: Tissue biomarkers for prognosis in pancreatic ductal adenocarcinoma: a systematic review and meta-analysis. Clin Cancer Res 17 3316-3331, 2011.

33. McKiernan E, McDermott EW, Evoy D, Crown J and Duffy MJ: The role of S100 genes in breast cancer progression. Tumour Biol 32: 441-450, 2011.

34. Jin L, Shen Q, Ding S, Jiang W, Jiang L and Zhu X: Immunohistochemical expression of Annexin A2 and S100A proteins in patients with bulky stage IB-IIA cervical cancer treated with neoadjuvant chemotherapy. Gynecol Oncol 126: 140-146, 2012.

35. Wolf S, Haase-Kohn C and Pietzsch J: S100A2 in cancerogenesis: A friend or a foe? Amino Acids 41: 849-861, 2011.

36. Ranganathan P, Agrawal A, Bhushan R, Chavalmane AK, Kalathur RK, Takahashi T and Kondaiah P: Expression profiling of genes regulated by TGF-beta: Differential regulation in normal and tumour cells. BMC Genomics 8: 98, 2007.

37. Naz S, Ranganathan P, Bodapati P, Shastry AH, Mishra LN and Kondaiah P: Regulation of S100A2 expression by TGF- $\beta$ induced MEK/ERK signalling and its role in cell migration/ invasion. Biochem J 447: 81-91, 2012.

38. Giráldez MD, Lozano JJ, Cuatrecasas M, Alonso-Espinaco V, Maurel J, Mármol M, Hörndler C, Ortego J, Alonso V, Escudero P, et al: Gene-expression signature of tumor recurrence in patients with stage II and III colon cancer treated with 5-fluoruracil-based adjuvant chemotherapy. Int J Cancer 132: 1090-1097, 2013.

39. Haller DG, Tabernero J, Maroun J, de Braud F, Price T, Van Cutsem E, Hill M, Gilberg F, Rittweger K and Schmoll HJ: Capecitabine plus oxaliplatin compared with fluorouracil and folinic acid as adjuvant therapy for stage III colon cancer. J Clin Oncol 29: 1465-1471, 2011.

40. Gao P, Song YX, Wang ZN, Xu YY, Tong LL, Sun JX, Yu M and $\mathrm{Xu}$ HM: Is the prediction of prognosis not improved by the seventh edition of the TNM classification for colorectal cancer? Analysis of the surveillance, epidemiology, and end results (SEER) database. BMC Cancer 13: 123, 2013. 